\title{
Correction to: Parents' Planning for Physical Activity for their Pre- School Aged Children: The Role of Psycho-Social Mediators and Moderators
}

\author{
Kyra Hamilton ${ }^{1,2} \cdot$ Ralf Schwarzer ${ }^{3,4}$
}

Published online: 11 May 2018

(c) Springer Science+Business Media, LLC, part of Springer Nature 2018

\section{Correction to: Journal of Child and Family Studies} https://doi.org/10.1007/s10826-017-0893-3

The original version of this article unfortunately contained a mistake. The spelling of the first author's name was incorrect. It should read as Kyra Hamilton.

The original article can be found online at https://doi.org/10.1007/ s10826-017-0893-3.

Kyra Hamilton

kyra.hamilton@griffith.edu.au

1 School of Applied Psychology, Menzies Health Institute Queensland, Griffith University, Southport, QLD, Australia

2 School of Psychology and Speech Pathology, Health Psychology and Behavioural Medicine Research Group, Curtin University, Bentley, WA, Australia

3 Department of Educational Science and Psychology, Freie Universität Berlin, Berlin, Germany

4 Department of Clinical, Health, and Rehabilitation Psychology, SWPS University of Social Sciences and Humanities,

Wroclaw, Poland 